\title{
Mycothalli of the hepatic Barbilophozia hatcheri in Antarctica: distribution and identities of mycobionts
}

\author{
K.K. NEWSHAM ${ }^{\mathrm{a},{ }^{*}}$, W.P. GOODALL-COPESTAKE ${ }^{\mathrm{a}}$, R. OCHYRA ${ }^{\mathrm{b}}$, J. VÁŇA ${ }^{\mathrm{c}}$
}

5

${ }^{a}$ British Antarctic Survey, Natural Environment Research Council, High Cross, Madingley Road, Cambridge, CB3 OET, UK

${ }^{\mathrm{b}}$ Polish Academy of Sciences, Institute of Botany, Bryology Laboratory, UI Lubicz 46, PL-31512, Krakow, Poland

$10 \quad{ }^{\mathrm{C}}$ Charles University Prague, Department of Botany, Faculty of Science, Benátská 2, CZ-128 01 Prague 2, Czech Republic

* Corresponding author. Tel.: +44 (0)1223 221400; fax: +44 (0)1223 362616

E-mail address: kne@bas.ac.uk (K.K. Newsham)

15

\section{ABSTRACT}

Forty-four herbarium specimens of the hepatic Barbilophozia hatcheri, collected from across the entire range of the species in Antarctica (54-68 ${ }^{\circ} \mathrm{S}$ ), were examined for fungal colonisation. Mycothalli, consisting of hyaline hyphae in rhizoids or hyphal coils in rhizoid bases and stem medullary cells, were present in 42 specimens. The frequencies of mycothalli declined at higher latitudes and were associated positively with annual air temperatures. In contrast, the frequency of dark septate hyphae on stems increased at higher latitudes. Sequencing of ITS regions of fungal rRNA genes amplified from B. hatcheri from $54{ }^{\circ} \mathrm{S}, 61^{\circ} \mathrm{S}$ and $68{ }^{\circ} \mathrm{S}$ indicated that Cladophialophora species colonised plants at higher latitudes, but that most fungi had $>99 \%$ homology with members of Sebacinales clade B, with best matches to mycobionts of Barbilophozia lycopodioides, Lophoziopsis excisa and Protolophozia crispata. We propose the use of herbarium specimens of mycothalli as proxies for climate change in Antarctica.

Keywords: Antarctica, Barbilophozia hatcheri, climate change, herbarium, latitudinal transect, mycothalli, Sebacinales clade B

\section{Introduction}

Leafy liverworts belonging to the order Jungermanniales are frequently colonised by ascomycete or basidiomycete fungi forming structures closely resembling mycorrhizas (Read et al. 2000; Selosse 2005). Associations between leafy liverworts and fungi, which are characterised by hyphae in the shafts of rhizoid cells and hyphal coils in the bases of rhizoids and adjacent medullary cells, are termed mycothalli, denoting symbioses with potentially mutualistic benefits (Boullard 1988). The ascomycetes forming these associations, which usually colonise liverworts in the Cephaloziaceae, Cephaloziellaceae, Lepidoziaceae, Calypogeiaceae and Schistochilaceae, are typically found to be Rhizoscyphus ericae or its allies. In contrast, the basidiomycetes, which usually colonise members of the Lophoziaceae, Arnelliaceae, Geocalycaceae and Scapaniaceae, are usually identified as members of Sebacinales clade B (Bidartondo \& Duckett 2010; Pressel et al. 2010), fungi 
that also form endophytic associations and ericoid, orchid or cavendishioid mycorrhizas with a wide range of plant species (Weiß et al. 2004). Although knowledge has accumulated about mycothalli in temperate and tropical habitats, comparatively little is known of the occurrence of these associations in polar regions, where bryophytes are usually the dominant plant form. Hitherto, there have been only three reports of mycothalli from the Antarctic, where the association has been found in two species of hepatic (Chambers et al. 1999; Upson et al. 2007; Newsham \& Bridge 2010). Furthermore, little is known of the abiotic factors that control the frequencies of mycothalli, although the abundance of fungal structures in Cephaloziella varians is known to be associated with surface air temperature in the Antarctic (Newsham 2011).

Reporting the presence of fungi belonging to Sebacinales clade B in the hepatic Lophoziopsis (= Lophozia) excisa at Léonie Island in the southern maritime Antarctic, Newsham \& Bridge (2010) advocated the examination of further leafy liverwort species from the continent, including Barbilophozia hatcheri (Evans) Loeske, for colonisation by these fungi. Here, we report a study that examined herbarium specimens of $B$. hatcheri collected from across the entire latitudinal range of the plant species in Antarctica (54-68 ${ }^{\circ} \mathrm{S}$; Bednarek-Ochyra et al. 2000) for fungal colonisation. The aims of the study were to establish whether or not the frequencies of fungal structures alter with latitude and surface air temperature, and to determine the identities of the mycobionts present in the tissues of the liverwort.

\section{Materials and methods}

Forty-four air-dried specimens of B. hatcheri were sourced from the British Antarctic Survey's herbarium (AAS). The specimens had been collected from along a 2,312 km transect from South Georgia in the subAntarctic through to Léonie Island in the southern maritime Antarctic (Fig 1). Details of the locations from which the plants were sampled, and the years in which they were collected, are shown in Table 1.

\section{Distribution of mycobionts}

Specimens of B. hatcheri were sorted in water under a dissecting microscope, checking for the presence of underleaves and cilia at the bases of leaves. Any debris was removed from plants, which were then cleared for $24 \mathrm{~h}$ in $10 \% \mathrm{KOH}$ solution. The $\mathrm{KOH}$ was removed and the plants were washed three times in water. They were then bleached in a solution of hydrogen peroxide (7.5\%) and ammonium hydroxide (0.7\%) for $c .3 \mathrm{~min}$, after which they were washed several times in water and then acidified in $5 \%$ lactic acid for $1 \mathrm{~h}$. The acid was drawn off and the plants were placed in $0.01 \%$ aniline blue in lactic acid for $24 \mathrm{~h}$. They were then removed from the staining solution, excess stain was drawn off on absorbent tissue paper, and they were destained for at least $24 \mathrm{~h}$ in $80 \%$ lactic acid. Between 10 and 40 plants from each specimen were mounted on glass slides and were lightly squashed prior to observation under UV epifluorescence at $\times 400$ magnification (BX51 microscope, Olympus UK Ltd). The line intersection method (McGonigle et al. 1990) was used to measure the percentages of stem length colonised by (i) hyphal coils in rhizoid bases and stem medullary cells, (ii) hyaline septate hyphae in stem medullary cells and (iii) dark septate hyphae on stem surfaces. The percentage of rhizoids colonised by hyaline hyphae was also recorded. Between 20 and 152 (mean 67) intersects and between 20 and 188 (mean 81) rhizoids were examined per specimen for colonisation. In total, 3,076 intersects and 3,725 rhizoids were examined for colonisation by fungal structures. 
Linear regression analyses were used to test for associations between the frequencies of fungal

80 structures in the tissues of $B$. hatcheri and latitude. Data from collection sites that were located $\leq 2$ seconds of latitude $(1.9 \mathrm{~km})$ apart were grouped together in these analyses. Linear regressions were also used to test associations between the frequencies of fungal structures and the year in which each specimen had been collected, and the annual surface air temperatures recorded at eight research stations situated 0.1-110 km from the collection sites (Table 2). All air temperature data were extracted from the READER dataset (http://www.antarctica.ac.uk/met/READER/) except those from Palmer station, which were taken from Baker \& Stammerjohn (1995). In addition, one way ANOVA was used to compare the frequencies of fungal colonisation in B. hatcheri tissues sampled from the same location on Signy Island (Factory Cove, a.k.a. 'the Backslope') in 1985 and 2011.

\section{$90 \quad$ Identities of mycobionts}

Specimens of B. hatcheri collected from South Georgia, Signy Island and Léonie Island in 2011 (Table 1) were selected for molecular analyses. Healthy apical parts of stems of B. hatcheri were cleaned of any debris and were bleached for $5 \mathrm{~min}$ in a 10\% solution of commercial bleach (c. $0.5 \%$ sodium hypochlorite) prior to washing in 30 changes of sterile distilled water $(10 \mathrm{ml})$ on a vortexer set to maximum speed. Between washes, each of which lasted for $5 \mathrm{~min}$, water was drained from plant tissues on sterile mesh (1 mm). Tissues were homogenised with a TissueRuptor and DNA was extracted from the tissues using a DNeasy Plant Mini kit (both Qiagen, Hilden, Germany). PCR amplifications were carried out in $40 \mu$ l volumes, with concentrations of 200 $\mu \mathrm{M}$ of each dNTP, $1.5 \mathrm{mM}$ of $\mathrm{MgCl}_{2}, 0.5$ units of Taq polymerase and $0.5 \mu \mathrm{M}$ of each of the primers ITS1F (5'CTTGGTCATTTAGAGGAAGTAA-3'; Gardes \& Bruns 1993)/ITS4 (5’-TCCTCCGCTTATTGATATGC-3’;

100 White et al. 1990) and ITS1F/TW14 (5'-GCTATCCTGAGGGAAACTTC-3'; Cullings 1994). The PCR amplification programme for both primer sets consisted of denaturation at $94{ }^{\circ} \mathrm{C}$ for 5 min, followed by 35 cycles of denaturation at $94{ }^{\circ} \mathrm{C}$ for $1 \mathrm{~min}$, annealing at $54{ }^{\circ} \mathrm{C}$ for $1 \mathrm{~min}$ and elongation at $72{ }^{\circ} \mathrm{C}$ for $3 \mathrm{~min}$, followed by a final elongation step at $68^{\circ} \mathrm{C}$ for $10 \mathrm{~min}$ (PTC-225 Peltier thermal cycler, MJ Research Inc., Watertown, MA, USA). The amplicons from the ITS1F/TW14 reactions were then used as templates in a second round of amplification using the primer set ITS3Seb (5'-TGAGTGTCATTGTAATCTCAC-3'/TW13 (5'GGTCCGTGTTTCAAGACG-3'; White et al. 1990), which selectively amplifies the 5.8S-ITS2 and part of the 28S region of rRNA genes of fungi in the Sebacinales (Selosse et al. 2007). The PCR amplification program for this primer set consisted of denaturation at $94^{\circ} \mathrm{C}$ for $4 \mathrm{~min}$, followed by 35 cycles of denaturation at $94{ }^{\circ} \mathrm{C}$ for $30 \mathrm{~s}$, annealing at $53{ }^{\circ} \mathrm{C}$ for $30 \mathrm{~s}$ and elongation at $72{ }^{\circ} \mathrm{C}$ for $30 \mathrm{~s}$, followed by a final elongation step at $72{ }^{\circ} \mathrm{C}$

110 for $10 \mathrm{~min}$. Sub-samples of amplicons, stained with the nucleic acid stain GelRed (Biotum, Hayward, CA, USA), were visualised on $1.5 \%$ agarose gels. Negative controls, consisting of sterile water ( $1 \mu \mathrm{l})$ in place of template DNA, did not yield amplicons. All positive PCR amplicons were cloned and transformed using a TOPO TA Cloning Kit (Life Technologies, Paisley, UK) following the manufacturer's recommendations. The recombinant clones that were obtained were bidirectionally sequenced using forward and reverse M13 primers.

Forward and reverse chromatograms from each sequenced clone were edited, then assembled, and vector and primer sequences were trimmed using Geneious v.6.1.6 (Drummond et al. 2011). The resulting assembly sequences were deposited in GenBank under the accession numbers KF636367- KF636410. MegaBLAST searches (word size: 16 , maximum E value: $1 \times 10^{-10}$, maximum hits: 1000 ) of the GenBank 
database using the full length rRNA and ITS assembly sequences did not consistently recover the taxonomically closest ITS1 or ITS2 BLAST hits when these hits were short in length and the BLAST results were dominated by longer reads that included less variable rRNA genes from taxonomically distant accessions. Therefore, in order to optimise the likelihood of finding the most highly similar species matches in GenBank, we carried out further MegaBLAST searches, with the same settings as those given above, using only the ITS1 and ITS2 regions rather than the full length assembly. The resulting ITS-specific MegaBLAST GenBank matches were sorted into putative species groupings using BLASTclust analyses (http://toolkit.tuebingen.mpg.de/blastclust/). Parameters for the BLASTclust analyses were a sequence length coverage of $75 \%$ and a percentage identity threshold of 98\% and 97\% for ascomycetes and basidiomycetes, respectively (Blaalid et al. 2013).

Molecular phylogenies were estimated using the cloned sequences of the ITS1-5.8S-ITS2 region, generated from the ITS1F/ITS4 primer pair, together with GenBank matches to these sequences obtained from

130 the MegaBLAST searches. The ITS1-5.8S-ITS2 region - the primary use of which was for DNA barcoding was too variable to be of use in taxonomically broad phylogenies, and hence only the most similar GenBank matches were used. In order to select the most similar matches, we filtered the ITS1- and ITS2-specific MegaBLAST search results for DNA accessions that had both ITS1 and ITS2 BLAST hits with $>75 \%$ coverage and $>85 \%$ pairwise identity. The resulting DNA accessions were unambiguously aligned with the sequences

135 from this study to generate ascomycete and basidiomycete DNA matrices consisting of 83 taxa by 519 characters and 67 taxa by 594 characters, respectively. Neither matrix showed evidence of nucleotide heterogeneity, as assessed using SeqVis v.1.5 software (Ho et al. 2006). Suitable DNA substitution models were hence selected using jModeltest v.2.1.1 (Darriba et al. 2012). A TIM2 model with equal base frequencies and a gamma variable sites parameter was selected for use with both matrices, which were subsequently analysed by

140 maximum likelihood with GARLI v.0.96 (Zwickl 2006) and also by unweighted maximum parsimony with PAUP v.4.0b10 (Swofford 2002). Phylogeny support measures were generated using 1000 non-parametric bootstrap replicates.

\section{Results}

\section{Distribution of mycobionts}

Hyphal coils, which formed in stem medullary cells and the bases of rhizoid cells (Supplementary Fig S1), were more frequent in plants from lower latitudes. Coils were recorded in all specimens examined except that gathered from Lahille Island (Rils 4329). Lines of best fit from linear regression analyses indicated that the percentage of stem length colonised by hyphal coils declined significantly from $72 \%$ at $54{ }^{\circ} \mathrm{S}$ to $16 \%$ at $68{ }^{\circ} \mathrm{S}$ $\left(F_{1,13}=10.8 ; r^{2}\right.$ adj. $=41 \% ; P=0.006$; slope $-4.3 \%$; Fig 2a). The hyphae that formed coils were continuous with hyaline septate hyphae (1.5-2.0 $\mu \mathrm{m}$ diam.) colonising the shafts of rhizoid cells (Supplementary Fig S1). These hyphae apparently entered the rhizoid cells through their tips and rarely branched within the shaft of the cell (Supplementary Fig S1). Hyaline septate hyphae were found in rhizoids in all specimens, except for one that had been gathered from Signy Island (Rils 5213). The percentage of rhizoids colonised by hyaline hyphae also declined significantly from $80 \%$ to $25 \%$ between $54{ }^{\circ} \mathrm{S}$ and $68{ }^{\circ} \mathrm{S}$, respectively $\left(F_{1,13}=9.6 ; r^{2}\right.$ adj. $=38 \%$; $P=0.008$; slope -3.5\%; Fig 2b). Broader (2-4 $\mu \mathrm{m}$ diam.) dark septate hyphae were frequently observed on the stem surfaces of plants collected from higher latitudes. Regression analyses indicated that the percentage of stem length colonised by these hyphae increased from $9 \%$ at $54{ }^{\circ} \mathrm{S}$ to $77 \%$ at $68{ }^{\circ} \mathrm{S}\left(F_{1,13}=8.7 ; r^{2}\right.$ adj. $=36 \%$; 
$P=0.011$; slope 5.1\%; Fig 2c). The frequency of hyaline septate hyphae on the surfaces of stems and within

epidermal cells, which were of the same diameter as those present in rhizoids, did not alter along the transect $\left(F_{1,13}=1.8 ; r^{2}\right.$ adj. $=5 \% ; P>0.05$; data not shown). Regression analyses indicated that the frequencies of fungal colonisation of $B$. hatcheri tissues were not associated with the year of collection $\left(F_{1,18}=0-3.8\right.$; $r^{2}$ adj. $0-13 \%$; all $P>0.05)$. ANOVA similarly indicated no differences between the frequencies of fungal structures in plants sampled in 1985 and 2011 from Factory Cove on Signy Island $\left(F_{1,8}=0.02-1.28 ; r^{2}\right.$ adj. 0-3\%; all $\left.P>0.05\right)$. In $B$. hatcheri samples from Factory Cove in 1985 and 2011 ( $n=5$ in both years), the mean stem lengths ( \pm SEM) colonised by hyphal coils were $41.4 \%$ (11.5\%) and $46.4 \%$ (11.5\%), the frequencies of rhizoids colonised by hyaline hyphae were $46.8 \%$ (15.1\%) and 49.3\% (8.6\%), and the stem lengths occupied by dark septate hyphae were $31.0 \%$ (10.3\%) and 16.3\% (7.8\%), respectively (Fig 2a-c).

Regression analyses indicated that the frequencies of hyphal coils in stem and medullary cells and of hyaline hyphae in rhizoids were both positively associated with mean annual surface air temperatures (hyphal coils: $F_{1,6}=6.4 ; r^{2}$ adj. $=43 \% ; P=0.045$; slope $6.2 \%$, hyphae in rhizoids: $F_{1,6}=9.2 ; r^{2}$ adj. $=54 \% ; P=0.023$; slope 6.3\%; Fig 3a, b). The percentages of stem length colonised by hyaline or dark septate hyphae were not associated with mean annual air temperatures $\left(F_{1,6}=<2.7 ; r^{2}\right.$ adj. $<20 \%$; both $P>0.05$; data not shown).

\section{Identities of mycobionts}

All PCRs produced positive amplicons. A total of 44 sequences were obtained from the cloned PCR products, with 29 and 15 derived from the ITS1F/ITS4 and ITS3Seb/TW13 primer sets, respectively. Results from the initial MegaBLAST analyses using full length sequences indicated that eight of the 29 queries from the ITS1F/ITS4 primer set were members of the Ascomycota. One of these eight sequences was derived from plants

180 sampled from Signy Island and the remainder were obtained from Léonie Island (Supplementary Table S1). Ascomycete sequences were not obtained from specimens sampled from South Georgia. ITS1- and ITS2specific MegaBLAST analyses of the ascomycete sequences yielded > 86.9\% sequence identity matches to members of the Herpotrichiellaceae. Three sequences from Léonie Island (Léo2, Léo4 and Léo14) had 94.9\% ITS1 and >96\% ITS2 matches to accessions EU686075 and FN555433 (Supplementary Table S1), both of

185 which are sequences of fungi associated with species of Lophozia or Lophoziopsis from Antarctica or North America. BLASTclust analysis suggested that these identities were insufficient for species determinations but were sufficient to indicate the same genus. Another three ascomycete sequences from the same island (Léo1, Léo13 and Léo15) had 100\% ITS1 and >98.1\% ITS2 matches to Cladophialophora minutissima from moss tissues in Canadian bogs (EF016376 and EF016382-4). The ITS1 and ITS2 BLASTclust groups for these

190 sequences also included the ex-type strain of Cladophialophora humicola from a European arable soil (EU035408), with 98\% and 93\% matches to this sequence across the two regions, respectively, and two Cladophialophora clones from Arctic soils (HQ211827 and HQ211891). Two sequences (Sig1 and Léo16) had 86.9-94.2\% identities to accessions of C. minutissima or to those of fungal clones from cold soils, montane rock surfaces or lichens. Maximum likelihood and maximum parsimony phylogenetic analyses of the ascomycete

195 sequences generated the same suites of well-supported groups. Data from both methods were largely consistent with the BLASTclust groupings to Cladophialophora species, with the grouping of Léo2, Léo4 and Léo14 being supported in both analyses (Supplementary Fig S2). However, the grouping of sequence Léo15 with Léo1 
and Léo13 was not statistically supported (Supplementary Fig S2), even though these three sequences formed a single BLASTclust group (Supplementary Table S1).

The remaining 36 query sequences were all found to be members of the Basidiomycota. MegaBLAST and BLASTclust analyses of these sequences indicated that they all matched closely (>99\% ITS1 and ITS2 similarities) with those of fungi belonging to Sebacinales clade B (Supplementary Table S2). The single BLASTclust ITS1 group consisted of the accessions GQ907083, GQ907084, GQ907097 and GQ907138, members of Sebacinales clade B previously found in association with Lophoziopsis excisa and Barbilophozia 205 lycopodioides from Switzerland, L. excisa from the UK and Protolophozia crispata from Chile, respectively. The ITS2 group contained the accessions FN555434, FN555435, GQ907083 and GQ907138 (Supplementary Table S2), the former two of which were associated with $L$. excisa from Léonie Island. The data strongly suggest that the basidiomycete sequences generated in the present study are all members of the same species in Sebacinales clade B (Supplementary Table S2). Data from maximum likelihood and maximum parsimony

210 phylogenetic analyses produced similar phylogenies, and showed that the basidiomycete sequences from this study were resolved as a single well-supported group within Sebacinales clade B that contained the same accessions generated from the BLASTclust analysis, viz. GQ907083, GQ907084, GQ907097 and GQ907138 (Fig 4). Many of the most closely related fungi to the basidiomycetes present in Antarctic B. hatcheri were mycobionts of liverwort species from Northern Europe and Chile (Fig 4).

215

\section{Discussion}

The results reported here, showing reductions in the frequencies of colonised rhizoids and hyphal coils in the tissues of Barbilophozia hatcheri at higher latitudes, indicate that the distribution of a mycothallus alters significantly across the entire latitudinal range of the hepatic in Antarctica. These observations corroborate those of a previous study showing reductions in the frequencies of hyphal coils, but not of colonised rhizoids, in the tissues of the liverwort Cephaloziella varians at higher latitudes across a transect between South Georgia and south-eastern Alexander Island, $360 \mathrm{~km}$ south of Léonie Island (Newsham 2011). The slopes of these associations, derived from linear regression analyses, are similar for both hepatics, with changes of 3\%-4\% in the frequencies of hyphal coils per degree of latitude, and significant associations between hyphal coil

225 frequencies and mean annual surface air temperatures in both cases. Associations were not recorded here between the frequencies of mycothalli and the year in which specimens had been collected. However, it should be noted that inaccuracies may have been introduced into the analyses by changes in surface air temperatures in the maritime Antarctic, estimated at $0.2-0.5^{\circ} \mathrm{C}$ per decade (Turner et al. 2009), during the 34-year period over which the specimens were collected, particularly as the two end-members in the analyses (South Georgia and

230 Léonie Island) were sampled the most recently. Nevertheless, the data here agree closely with the previous study on C. varians, in which specimens were collected over several years, and in which $4.6 \%$ increases in hyphal coils were recorded per degree Celsius rise in mean annual surface air temperature (Newsham 2011), compared with the $6.2 \%$ increase in coils per degree Celsius rise in temperature recorded here. These data support previous studies showing the important influence of air temperature, with which liquid water availability is strongly associated in polar environments, on fungal distributions at high latitudes (Wollan et al. 2008; Newsham et al. 2009). They also corroborate previous data showing reductions in the frequencies of arbuscular mycorrhizal 
fungi, the main fungal symbionts of herbaceous plant species, in roots sampled from higher latitudes in the Arctic and Antarctic (Väre et al. 1992; Olsson et al. 2004; Upson et al. 2008).

In the present study, hyaline septate hyphae were found to enter the rhizoids of $B$. hatcheri at their tips,

240 from where they grew along rhizoid shafts and formed hyphal coils in the bases of rhizoid cells and adjacent medullary cells. These patterns of fungal colonisation are the same as those observed in $B$. hatcheri and related hepatics from Europe, viz. Orthocaulis attenuatus and O. floerkei (= Barbilophozia attenuata and B. floerkei), Schljakovia kunzeana (= B. kunzeana), Schljakovianthus quadrilobus (= B. quadriloba), Barbilophozia lycopodioides and B. barbata (Kottke et al. 2003; Duckett et al. 2006). Based on the presence of dolipores with

245 imperforate parenthesomes, these patterns of colonisation were initially ascribed to the basidiomycetes, and specifically the Sebacinales (Kottke et al. 2003; Duckett et al. 2006). Subsequent sequencing data confirmed that the fungi associated with these hepatics from Northern Europe or Chile, along with those associated with Diplophyllum, Lophozia, Scapania, Trilophozia, Nardia and Saccogyna spp. from Europe, South America or Asia, are members of Sebacinales clade B (Bidartondo \& Duckett 2010). The data reported here show 99\%-

$250100 \%$ homology between the ITS1 and ITS2 region sequences of the mycobionts in Antarctic B. hatcheri and these liverwort-associated members of Sebacinales clade B. Along with previous data showing the same fungi to be the mycobionts of Lophoziopsis excisa at Léonie Island (Newsham \& Bridge 2010), they show the presence of a second mycothallus formed by members of the clade in Antarctica. Together with studies showing the presence of Sebacinales clade B in soils and the roots of plants sampled from North America, South America,

255 Europe, Africa, Asia and Australia (Weiß et al. 2011), they also indicate that members of the clade have a worldwide distribution.

The occurrence of members of Sebacinales clade B is well documented in many families of higher plants, including the Ericaceae, Fabaceae, Lamiaceae, Orchidaceae and Poaceae (Weiß et al. 2004; Setaro et al. 2006; Selosse et al. 2007, 2009; Weiß et al. 2011). Given the frequent occurrence of these fungi in higher

260 plants, it is notable that each of the best matches to the Sebacinales clade B sequences derived from the present study were to fungi previously found in association with the leafy liverworts B. lycopodioides, L. excisa and Protolophozia crispata (Bidartondo \& Duckett 2010; Newsham \& Bridge 2010). This observation supports the distinct clade of Sebacinales associated with the leafy liverworts Pseudolophozia (= Lophozia) sudetica, Schistochilopsis (= Lophozia) incisa and Calypogeia muelleriana found in a previous study (Weiß et al. 2004).

265 However, to test the idea that there may be a phylogenetically distinct clade of leafy liverwort-associated Sebacinales (Newsham \& Bridge 2010), more DNA sequence data are required from genomic regions that are less variable than the ITS region used in this study in order to resolve deeper relationships among, and possibly within, this putative clade of fungi.

The data reported here indicate an increase in the frequency of dark septate hyphae on the stem surfaces of $B$. hatcheri at more southerly latitudes, corresponding with an increase in the frequency of fungi with ITS1 and ITS2 region sequences similar to those of the dematiaceous ascomycete Cladophialophora. The ITS1 regions of three sequences amplified from $B$. hatcheri from Léonie Island matched precisely with that of $C$. minutissima isolated from the tissues of the mosses Polytrichum juniperinum and Aulacomnium palustre inhabiting Canadian Sphagnum bogs (Davey \& Currah 2007), and had >98\% homology with the ex-type strain 275 of C. humicola, from European arable soil (Crous et al. 2007). The data here confirm the presence of Cladophialophora and related fungi in the tissues of L. excisa from Léonie Island and a species of Lophozia 
from North America (Davis \& Shaw 2008; Newsham \& Bridge 2010) and support the view that members of the Chaetothyriales (such as Cladophialophora) become more frequent in disturbed or stressed environments (Lindahl et al. 2010). As for hyphal coils, the changes with latitude in the frequencies of dark septate hyphae on the stem surfaces of $B$. hatcheri were similar to those reported for C. varians (Newsham 2011), with 4\%-5\% increases in stem length occupied by these hyphae in both species for each degree of latitude further south. These findings support the view that fungal hyphae become increasingly melanised in cold and arid habitats in order to confer resistance to low temperatures and desiccation, broadening the ecological niches occupied by fungi (Jumpponen \& Trappe 1998; Robinson 2001).

A previous study on arbuscular mycorrhizal fungi in the roots of Arctic plants suggested that archives of herbarium material represent untapped resources for determining the spatial and temporal responses of fungi to climatic change (Ormsby et al. 2007). The data reported here support this view. Recent estimates of the rates of climate change in the maritime Antarctic indicate a $0.2{ }^{\circ} \mathrm{C}$ decade ${ }^{-1}$ rise in annual surface air temperature since the 1950s at Orcados station on Laurie Island, $45 \mathrm{~km}$ to the east of Signy Island (Turner et al. 2009). Since 1985 there has hence been a rise in mean annual surface air temperature in the region of Signy Island of c. 0.5 ${ }^{\circ} \mathrm{C}$, which, assuming increases reported here of $6.2 \%-6.3 \%$ in the frequencies of hyphal coils and colonised rhizoids for each degree Celsius change in surface air temperature, would have elicited increases of $c$. $3 \%$ in the frequencies of these structures in B. hatcheri at Signy Island over the last two and a half decades. This estimate agrees reasonably well with the observed data: in 1985 and 2011, the frequencies of hyphal coils in the tissues of $B$. hatcheri were $41.4 \%$ and $46.4 \%$, and those of colonised rhizoids were $46.8 \%$ and $49.3 \%$, respectively. There was considerable variation associated with these measurements, and hence no differences were found between 1985 and 2011 in the frequencies of mycothalli in B. hatcheri at Signy Island. Given this variation, and assuming the same level of replication as used here, it may be several decades before any statistically significant differences become apparent, relative to the latter decades of the $20^{\text {th }}$ century, in the frequencies of mycothalli in maritime Antarctic hepatics. Nevertheless, with previous research similarly having shown significant associations between mean annual air temperatures and the frequency of hyphal coils in Cephaloziella varians (Newsham 2011), there is apparently potential for using herbarium specimens of mycothalli as proxies for decadal to centennial climate change impacts in Antarctica.

\section{Acknowledgements}

Funding was provided by the Natural Environment Research Council through the British Antarctic Survey’s Coastal and Terrestrial workpackage. Ron Lewis Smith, Ken Richard, Bill Hankinson, Alistair Moffat and Cora de Leeuw collected the specimens of $B$. hatcheri. The crew of RRS James Clark Ross assisted with transport to and from South Georgia and Signy Island, and Dave Hunt and Russ Ladkin assisted with fieldwork on Léonie

310 Island. Magda Biszczuk drew Fig 1. Marc-André Selosse and an anonymous reviewer provided helpful comments on the manuscript. All are gratefully acknowledged.

\section{References}

Baker KS, Stammerjohn S, 1995. Palmer LTER: Palmer Station weather records. Antarctic Journal of the 
Bednarek-Ochyra H, Váňa J, Ochyra JVR, Smith RIL, 2000. The liverwort flora of Antarctica. Institute of Botany, Polish Academy of Sciences, Cracow.

Bidartondo MI, Duckett JG, 2010. Conservative ecological and evolutionary patterns in liverwort-fungal symbioses. Proceedings of the Royal Society B 277: 485-492.

320

Blaalid R, Kumar S, Nilsson RH, Abarenkov K, Kirk PM, Kauserud H, 2013. ITS1 versus ITS2 as DNA metabarcodes for fungi. Molecular Ecology Resources 13: 218-224.

Boullard B, 1988. Observations on the coevolution of fungi with hepatics. In: Pyrozynski KA (ed), Coevolution 325 of Fungi with Plants and Animals. Academic Press, London, pp. 107-124.

Chambers SM, Williams PG, Seppelt RD, Cairney JWG, 1999. Molecular identification of Hymenoscyphus sp. from rhizoids of the leafy liverwort Cephaloziella exiliflora in Australia and Antarctica. Mycological Research 103: 286-288.

Crous PW, Schubert K, Braun U, de Hoog GS, Hocking AD, Shin HD, Groenewald JZ, 2007. Opportunistic, 330 human-pathogenic species in the Herpotrichiellaceae are phenotypically similar to saprobic or phytopathogenic species in the Venturiaceae. Studies in Mycology 58: 185-217.

Cullings KW, 1994. Molecular phylogeny of the Monotropoideae (Ericaceae) with a note on the placement of the Pyroloideae. Journal of Evolutionary Biology 7: 501-516.

335

Darriba D, Taboada GL, Doallo R, Posada D, 2012. jModelTest 2: more models, new heuristics and parallel computing. Nature Methods 9: 772.

Davey ML, Currah RS, 2007. A new species of Cladophialophora (hyphomycetes) from boreal and montane bryophytes. Mycological Research 111: 106-116.

Davis EC, Shaw AJ, 2008. Biogeographic and phylogenetic patterns in diversity of liverwort-associated endophytes. American Journal of Botany 95: 914-924.

345 Drummond AJ, Ashton B, Buxton S, Cheung M, Cooper A, Duran C, Field M, Heled J, Kearse M, Markowitz S, Moir R, Stones-Havas S, Sturrock S, Thierer T, Wilson A, 2011. Geneious version 6.1 created by Biomatters. Available from http://www.geneious.com

Duckett JG, Russell J, Ligrone R, 2006. Basidiomycetous endophytes in jungermannialean (leafy) liverworts 350 have novel cytology and species-specific host ranges: a cytological and experimental study. Canadian Journal of Botany 84:1075-1093. 
Gardes M, Bruns TD, 1993. ITS primers with enhanced specificity for Basidiomycetes - application to the identification of mycorrhizae and rusts. Molecular Ecology 2: 113-118.

355

Ho JWK, Adams CE, Lew JB, Matthews TJ, Ng CC, Shahabi-Sirjani A, Tan LH, Zhao Y, Easteal S, Wilson SR, Jermiin LS, 2006. SeqVis: visualization of compositional heterogeneity in large alignments of nucleotides. Bioinformatics 22: 2162-2163.

Jumpponen A, Trappe JM, 1998. Dark septate endophytes: a review of facultative biotrophic root-colonizing fungi. New Phytologist 140: 295-310.

Kottke I, Beiter A, Weiß M, Haug I, Oberwinkler F, Nebel M, 2003. Heterobasidiomycetes form symbiotic associations with hepatics: Jungermanniales have sebacinoid mycobionts while Aneura pinguis (Metzgeriales) is associated with a Tulasnella species. Mycological Research 107: 957-968.

Lindahl BD, de Boer W, Finlay RD, 2010. Disruption of root carbon transport into forest humus stimulates fungal opportunists at the expense of mycorrhizal fungi. The ISME Journal 4: 872-881.

McGonigle TP, Miller MH, Evans DG, Fairchild GL, Swann JA, 1990. A new method which gives an objective measure of colonization of roots by vesicular-arbuscular mycorrhizal fungi. New Phytologist 155: 495-501.

Newsham KK, 2011. Structural changes to a mycothallus along a latitudinal transect through the maritime and sub-Antarctic. Mycorrhiza 21: 231-236.

375

Newsham KK, Upson R, Read DJ, 2009. Mycorrhizas and dark septate endophytes in polar regions. Fungal Ecology 2: 10-20.

Newsham KK, Bridge PD, 2010. Sebacinales are associates of the leafy liverwort Lophozia excisa in the southern maritime Antarctic. Mycorrhiza 20: 307-313.

Olsson PA, Eriksen B, Dahlberg A, 2004. Colonization by arbuscular mycorrhizal and fine endophytic fungi in herbaceous vegetation in the Canadian High Arctic. Canadian Journal of Botany 82: 1547-1556.

Ormsby A, Hodson E, Li Y, Basinger J, Kaminskyj S, 2007. Quantitation of endorhizal fungi in High Arctic tundra ecosystems through space and time: the value of herbarium archives. Canadian Journal of Botany 85: 599-606.

Pressel S, Bidartondo MI, Ligrone R, Duckett JG, 2010. Fungal symbioses in bryophytes: new insights in the twenty first century. Phytotaxa 9: 238-253. 
Read DJ, Duckett JG, Francis R, Ligrone R, Russell A, 2000. Symbiotic fungal associations in 'lower' land plants. Philosophical Transactions of the Royal Society of London B 355: 815-831.

395 Robinson CH, 2001. Physiological and ecological adaptations to survival at low temperatures in Arctic and Antarctic fungi. New Phytologist 151: 341-353.

Selosse M-A, 2005. Are liverworts imitating mycorrhizas? New Phytologist 165: 345-349.

400 Selosse M-A, Setaro S, Glatard F, Richard F, Urcelay C, Weiß M, 2007. Sebacinales are common mycorrhizal associates of Ericaceae. New Phytologist 174: 864-878.

Selosse M-A, Dubois M-P, Alvarez M, 2009. Do Sebacinales commonly associate with plants roots as endophytes? Mycological Research 113: 1062-1069.

405

Setaro S, Weiß M, Oberwinkler F, Kottke I, 2006. Sebacinales form ectendomycorrhizas with Cavendishia nobilis, a member of the Andean clade of Ericaceae, in the mountains rain forest of southern Ecuador. New Phytologist 169: 355-365.

410 Swofford DL, 2002. PAUP (phylogenetic analysis using parsimony), version 4.0b10. Sunderland: Sinauer Associates.

Turner J, Bindschlader RA, Convey P, di Prisco G, Fahrbach E, Gutt J, Hodgson DA, Mayewski PA, Summerhayes C, 2009. Antarctic Climate Change and the Environment. Scientific Committee on Antarctic

415 Research, Scott Polar Research Institute, Cambridge, UK.

Upson R, Read DJ, Newsham KK, 2007. Widespread association between the ericoid mycorrhizal fungus Rhizoscyphus ericae and a leafy liverwort in the maritime and sub-Antarctic. New Phytologist 176: 460-471.

Upson R, Newsham KK, Read DJ, 2008. Root-fungal associations of Colobanthus quitensis and Deschampsia antarctica in the maritime and sub-Antarctic. Arctic, Antarctic and Alpine Research 40: 592-599.

Väre H, Vestberg M, Eurola S, 1992. Mycorrhiza and root associated fungi in Spitsbergen. Mycorrhiza 1: 93104.

425

Weiß M, Selosse M-A, Rexer K-H, Urban U, Oberwinkler F, 2004. Sebacinales: a hitherto overlooked cosm of heterobasidiomycetes with a broad mycorrhizal potential. Mycological Research 108: 1003-1010.

Weiß M, Sýkorová Z, Garnica S, Riess K, Martos F, Krause C, Oberwinkler F, Bauer R, Redecker D, 2011. 
White TJ, Bruns TD, Lee SB, Taylor JW, 1990. Amplification and direct sequencing of fungal ribosomal RNA genes for phylogenetics. In: Innis MA, Gelfand H, Sninsky JS, White TJ (eds), PCR Protocols: a guide to methods and applications. Academic Press, Berkeley, pp. 315-321.

435

Wollan AK, Bakkestuen V, Kauserud H, Gulden G, Halvorsen R, 2008. Modelling and predicting fungal distribution patterns using herbarium data. Journal of Biogeography 35: 2298-2310.

Zwickl DJ, 2006. Genetic algorithm approaches for the phylogenetic analysis of large biological sequence 440 datasets under the maximum likelihood criterion. Ph. D. dissertation, the University of Texas at Austin. 
Figure legends

Fig 1 - map showing the locations of the sites from which the herbarium specimens were collected. Site numbers correspond to those shown in Tables 1 and 2 and Fig 3.

Fig 2 - (a) the percentage of stem length colonised by hyphal coils, (b) the percentage of rhizoids colonised by hyaline septate hyphae and (c) the percentage of stem length colonised by dark septate (DS) hyphae in the tissues of $B$. hatcheri as a function of latitude. Dotted lines are lines of best fit derived from linear regression analyses. Values on the $y$-axis are either single points or are means of 2-10 replicates \pm SEM. Open and filled symbols at $61^{\circ} \mathrm{S}$ represent values for specimens collected from Factory Cove on Signy Island in 1985 and 2011 , respectively.

Fig 3 - (a) the percentage of stem length colonised by hyphal coils and (b) the percentage of rhizoids colonised by hyaline septate hyphae as a function of mean annual surface air temperature recorded at eight research stations. Dotted lines are lines of best fit derived from linear regression analyses. Values on the $x$-axis are means of 14-22 years \pm SEM. Those on the $y$-axis are means of 2-14 replicates \pm SEM. Numerals correspond to the site numbers shown in Tables 1 and 2.

Fig 4 - midpoint-rooted, maximum likelihood phylogram obtained from the alignment of ITS1-5.8S-ITS2 region sequences of basidiomycetes amplified from Antarctic Barbilophozia hatcheri with those of fungi in Sebacinales clade B having $>75 \%$ ITS1 and ITS2 coverage and $>85 \%$ pairwise identity with query sequences. GenBank accession numbers of reference sequences are shown, along with the plant species host or substrate and the country of origin in parentheses. Reference sequences marked in bold are accessions of fungi found in association with liverwort species. Symbols at branch nodes indicate bootstrap support at $>50 \%(\square)>80 \%(\circ)$ and at $100 \%(\bullet)$ in both maximum parsimony and maximum likelihood analyses. Abbreviations: SG, South Georgia; Sig, Signy Island; Léo, Léonie Island. 
Table 1. Herbarium specimens of Barbilophozia hatcheri examined in the study

\begin{tabular}{|c|c|c|c|c|}
\hline Site no. & Location & Latitude and longitude & Year collected & AAS accession no. \\
\hline 1 & South Georgia & $54^{\circ} 17^{\prime} \mathrm{S} ; 36^{\circ} 31^{\prime} \mathrm{W}$ & 2011 & KN 1-KN 5 \\
\hline \multirow[t]{2}{*}{2} & Signy Island & $60^{\circ} 42^{\prime} \mathrm{S} ; 45^{\circ} 36^{\prime} \mathrm{W}$ & 1985 & Rils 5209-Rils 5213 \\
\hline & Signy Island & $60^{\circ} 42^{\prime} \mathrm{S} ; 45^{\circ} 36^{\prime} \mathrm{W}$ & 2011 & KN 143-KN 147 \\
\hline 3 & King George Island & $62^{\circ} 06^{\prime} \mathrm{S} ; 58^{\circ} 29^{\prime} \mathrm{W}$ & 1980 & Ochyra 1758 \\
\hline 4 & King George Island & $62^{\circ} 07^{\prime} \mathrm{S} ; 58^{\circ} 24^{\prime} \mathrm{W}$ & 1980 & Ochyra 1757 \\
\hline 5 & King George Island & $62^{\circ} 13^{\prime} \mathrm{S} ; 58^{\circ} 25^{\prime} \mathrm{W}$ & 1980 & Ochyra 1730 \\
\hline 6 & Livingston Island & $62^{\circ} 37^{\prime} \mathrm{S} ; 61^{\circ} 09^{\prime} \mathrm{W}$ & 1991 & Richard 44 \\
\hline 7 & Livingston Island & $62^{\circ} 39^{\prime} \mathrm{S} ; 61^{\circ} 10^{\prime} \mathrm{W}$ & 1991 & Richard 28, Richard 29 \\
\hline 8 & Brabant Island & $64^{\circ} 02^{\prime} \mathrm{S} ; 62^{\circ} 35^{\prime} \mathrm{W}$ & 1985 & Moffat 61, Moffat 76 \\
\hline 9 & Brabant Island & $64^{\circ} 17^{\prime} \mathrm{S} ; 62^{\circ} 20^{\prime} \mathrm{W}$ & 1984 & Hankinson 189 \\
\hline 10 & Omega Island & $64^{\circ} 20^{\prime} \mathrm{S} ; 62^{\circ} 56^{\prime} \mathrm{W}$ & 1981 & Rils 4126 \\
\hline 11 & Gamma Island & $64^{\circ} 20^{\prime} \mathrm{S} ; 63^{\circ} 00^{\prime} \mathrm{W}$ & 1981 & Rils 4153 \\
\hline 12 & Hunt Island & $64^{\circ} 20^{\prime} \mathrm{S} ; 62^{\circ} 09^{\prime} \mathrm{W}$ & 1985 & Moffat 51 \\
\hline \multirow[t]{3}{*}{13} & Cuverville Island & $64^{\circ} 41^{\prime} \mathrm{S} ; 62^{\circ} 38^{\prime} \mathrm{W}$ & 1981 & Rils 4212 \\
\hline & Cuverville Island & $64^{\circ} 41^{\prime} \mathrm{S} ; 62^{\circ} 38^{\prime} \mathrm{W}$ & 1993 & de Leeuw 12 , de Leeuw 13 \\
\hline & Cuverville Island & $64^{\circ} 41^{\prime} \mathrm{S} ; 62^{\circ} 38^{\prime} \mathrm{W}$ & 2005 & Rils 11938, Rils 11953 \\
\hline 14 & Danco Coast & $64^{\circ} 44^{\prime} \mathrm{S} ; 62^{\circ} 33^{\prime} \mathrm{W}$ & 1981 & Rils 4225 \\
\hline 15 & Joubin Island & $64^{\circ} 47^{\prime} \mathrm{S} ; 64^{\circ} 26^{\prime} \mathrm{W}$ & 1977 & Rils 1990, Rils 1998 \\
\hline 16 & Uruguay Island & $65^{\circ} 14^{\prime} \mathrm{S} ; 64^{\circ} 14^{\prime} \mathrm{W}$ & 1981 & Rils 4274, Rils 4275 \\
\hline 17 & Rasmussen Island & $65^{\circ} 15^{\prime} \mathrm{S} ; 64^{\circ} 06^{\prime} \mathrm{W}$ & 1977 & Rils 1926 \\
\hline 18 & Lahille Island & $65^{\circ} 32^{\prime} \mathrm{S} ; 64^{\circ} 22^{\prime} \mathrm{W}$ & 1981 & Rils 4329 \\
\hline 19 & Takaki Point & $65^{\circ} 32^{\prime} \mathrm{S} ; 64^{\circ} 14^{\prime} \mathrm{W}$ & 1981 & Rils 4349, Rils 4391 \\
\hline 20 & Léonie Island & $67^{\circ} 36^{\prime} \mathrm{S} ; 68^{\circ} 20^{\prime} \mathrm{W}$ & 2011 & KN 148-KN 150 \\
\hline
\end{tabular}

See Fig 1. Further details of the specimens and the habitats from which they were collected can be accessed at

http://apex.nerc-bas.ac.uk/f?p=252:1

'KN' and 'Rils’ denote collections by K. Newsham and R.I.L. Smith, respectively. 
Table 2. Research stations at which surface air temperature data were recorded and their distances from collection sites

\begin{tabular}{|c|c|c|c|c|c|}
\hline Station & Island & Latitude and longitude & $\begin{array}{l}\text { Years in which } \\
\text { data were recorded }\end{array}$ & Site no. & $\begin{array}{l}\text { Distance from } \\
\text { station to site } \\
(\mathrm{km})\end{array}$ \\
\hline Grytviken & South Georgia & $54^{\circ} 17^{\prime} \mathrm{S} ; 36^{\circ} 31^{\prime} \mathrm{W}$ & 1985-1988; 2002-2011 & 1 & 1 \\
\hline Signy & Signy Island & $60^{\circ} 42^{\prime} \mathrm{S} ; 45^{\circ} 36^{\prime} \mathrm{W}$ & 1982-1995 & 2 & 0.1 \\
\hline Comandante Ferraz & King George Island & $62^{\circ} 05^{\prime} \mathrm{S} ; 58^{\circ} 23^{\prime} \mathrm{W}$ & 1992-2009 & 3,4 & $4,5,6^{a}$ \\
\hline Jubany & King George Island & $62^{\circ} 14^{\prime} \mathrm{S} ; 58^{\circ} 40^{\prime} \mathrm{W}$ & 1988-2001; 2005-2008 & 5 & 13 \\
\hline Capitan Arturo Prat & Greenwich Island & $62^{\circ} 30^{\prime} \mathrm{S} ; 59^{\circ} 41^{\prime} \mathrm{W}$ & 1980-1990; 1993-2003 & 6,7 & 78 \\
\hline Palmer & Anvers Island & $64^{\circ} 46^{\prime} \mathrm{S} ; 64^{\circ} 05^{\prime} \mathrm{W}$ & 1974-1996 & $8-15$ & $12,70,110^{\mathrm{a}}$ \\
\hline Vernadsky & Galindez Island & $65^{\circ} 15^{\prime} \mathrm{S} ; 64^{\circ} 15^{\prime} \mathrm{W}$ & 1990-2011 & $16-19$ & $5,20,38^{\mathrm{a}}$ \\
\hline Rothera & Léonie Island & $67^{\circ} 34^{\prime} \mathrm{S} ; 68^{\circ} 08^{\prime} \mathrm{W}$ & 1990-2011 & 20 & 10 \\
\hline
\end{tabular}




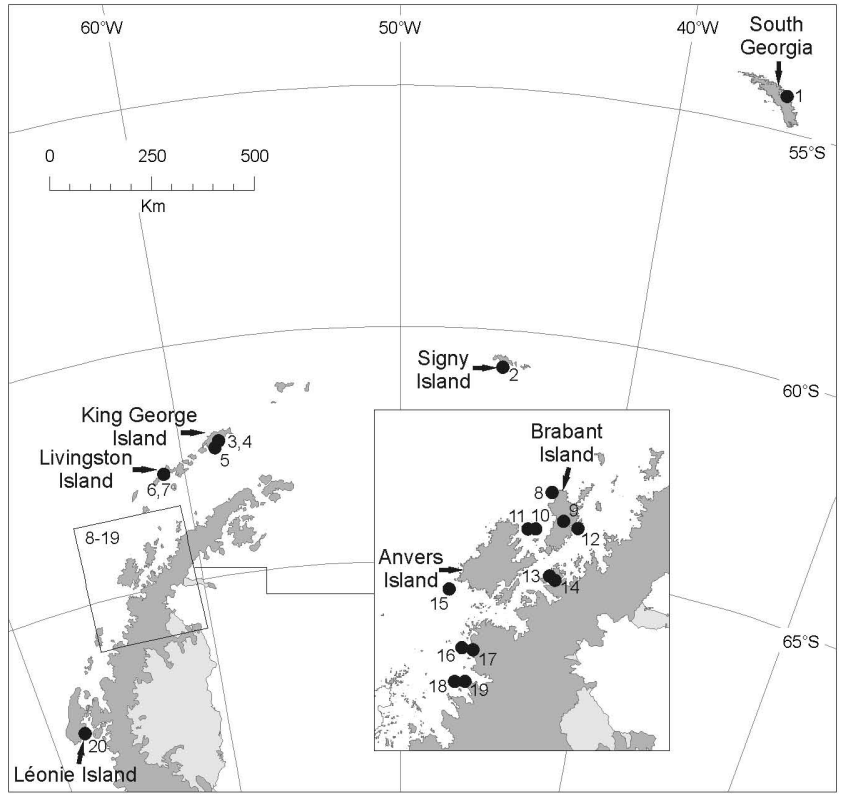




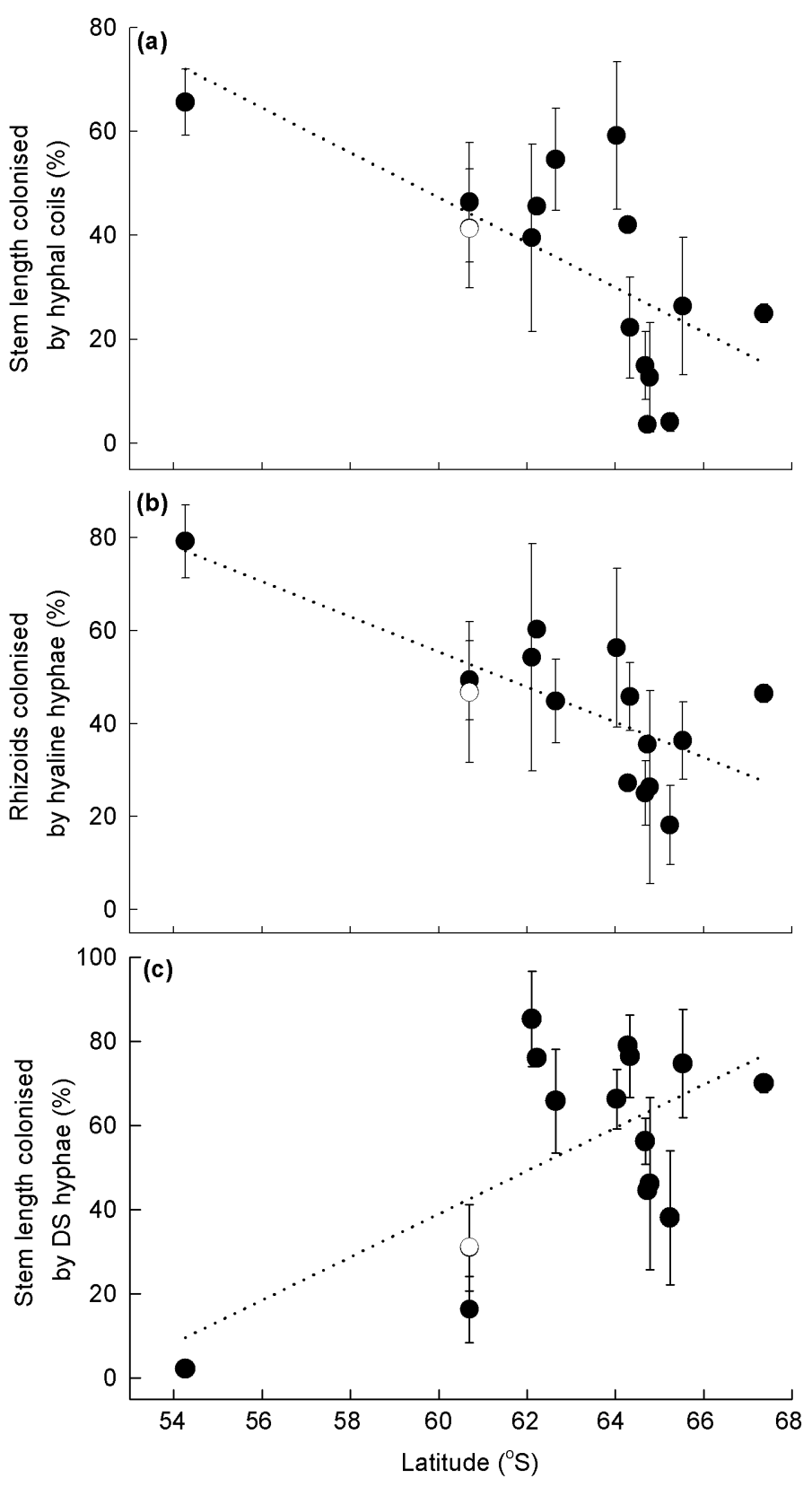



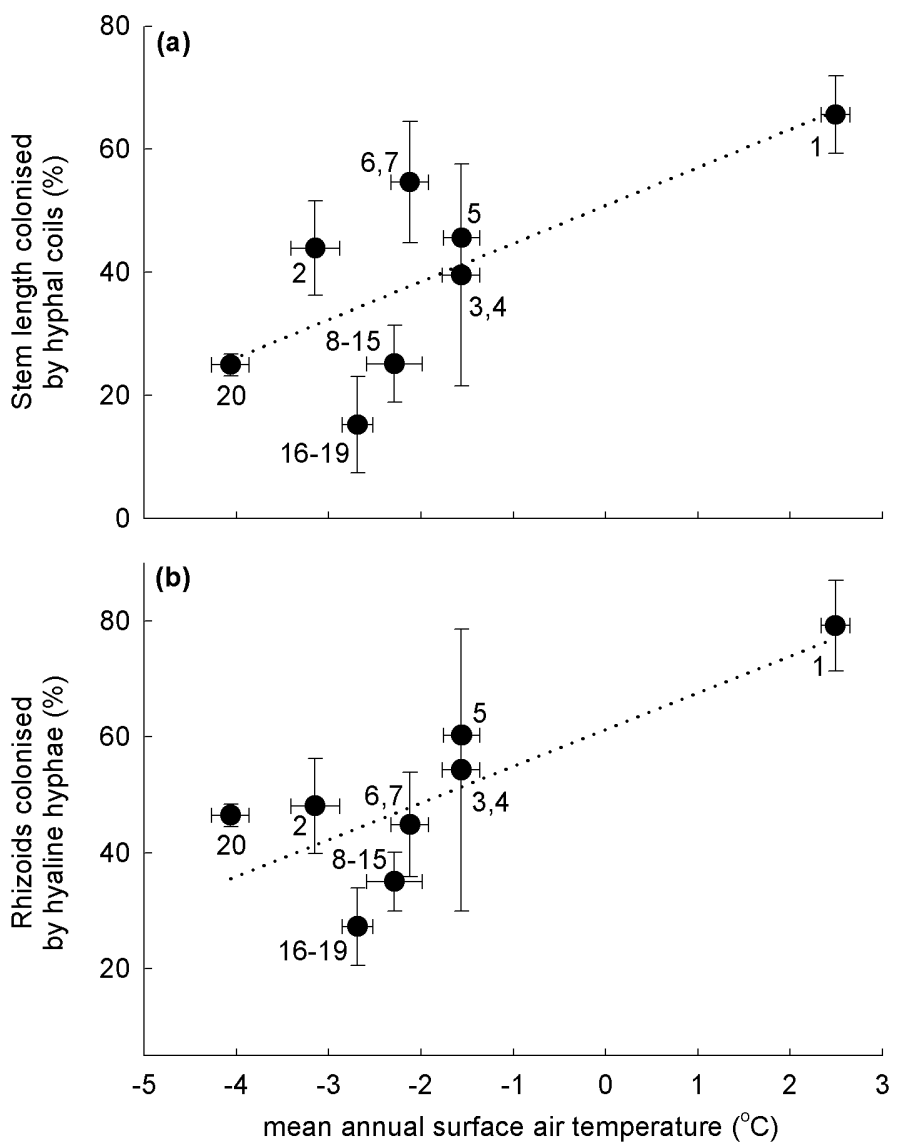


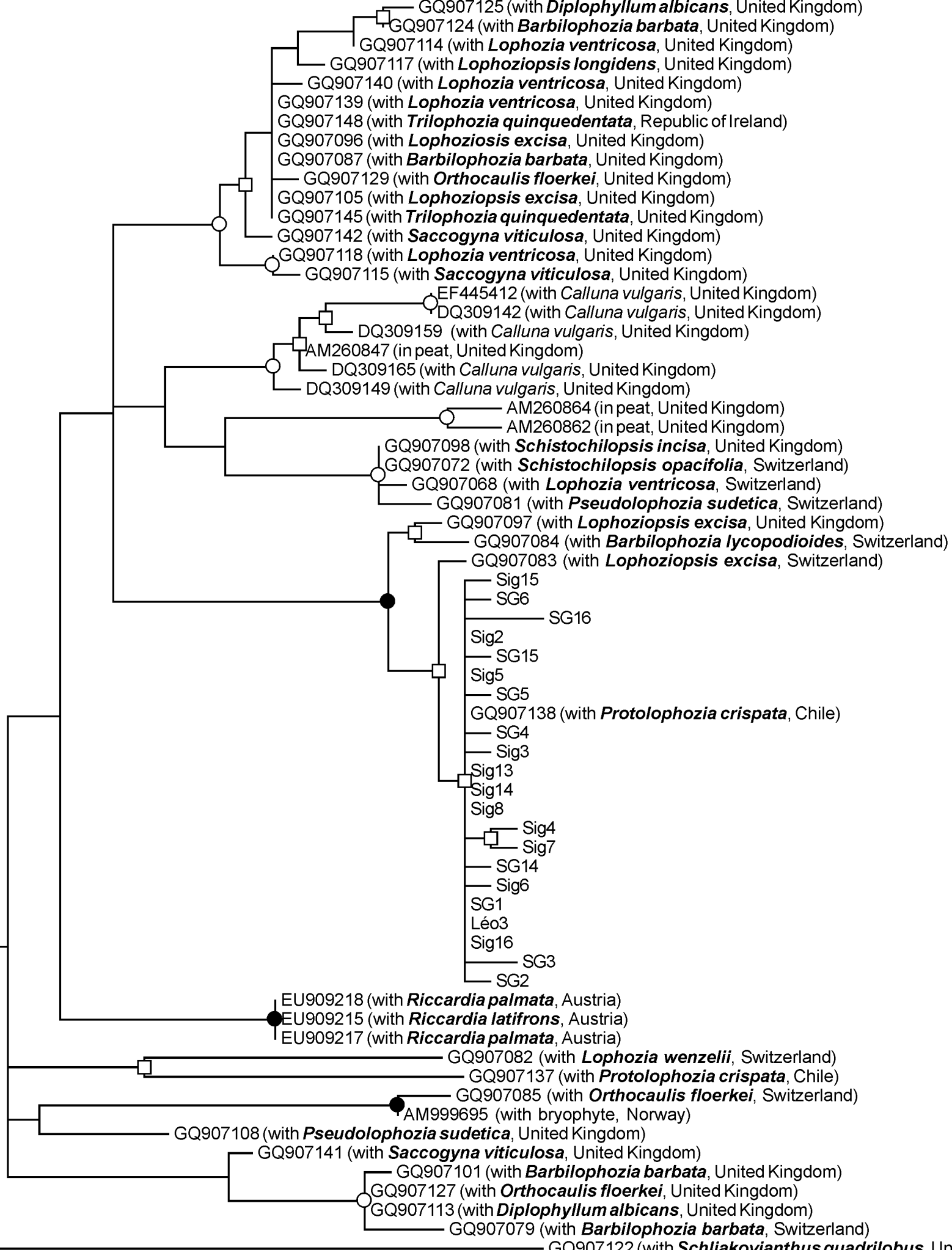

- GQ907125 (with Diplophyllum albicans, United Kingdom)

GQ907140 (with Lophozia ventricosa, United Kingdom)

Q907139 (with Lophozia ventricosa, United Kingdom)

GQ907148 (with Trilophozia quinquedentata, Republic of Ireland)

GQ907096 (with Lophoziosis excisa, United Kingdom)

GQ907087 (with Barbilophozia barbata, United Kingdom)

Q907118 (with Lophozia ventricosa,

EF445412 (with Calluna vulgaris, United Kingdom)

DQ309142 (with Calluna vulgaris, United Kingdom)

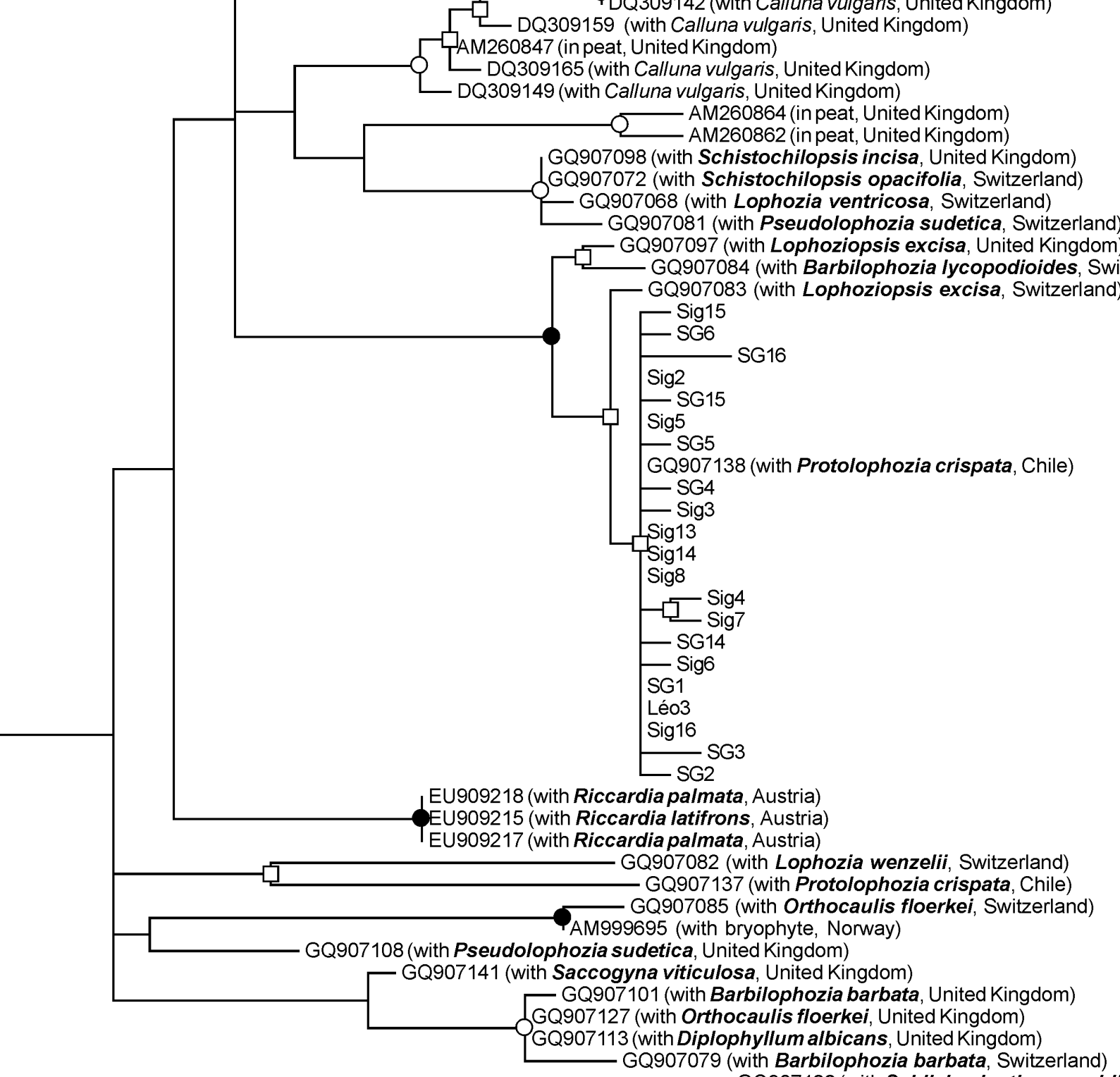

GQ907134 (with Diplophyllum albicans, United Kingdom) 
Supplementary Table S1. MegaBLAST hits and BLASTclust groups for ITS1 and ITS2 ascomycete sequences generated using the ITS1F/ITS4 primer pair

\begin{tabular}{|c|c|c|c|c|c|}
\hline Sequences & $\begin{array}{c}\text { ITS1 MegaBLAST top } \\
\text { hit(s) }\end{array}$ & ITS1 BLASTclust group & ITS2 MegaBLAST top hit(s) ${ }^{*}$ & ITS2 BLASTclust group & Species inference \\
\hline Sig1 & $\begin{array}{c}\text { 92.7\%, 100\%, 2.39e-64 to } \\
\text { AY843170, EF016376, } \\
\text { EF016382-4, FJ553294 } \\
\text { and JN032522 }\end{array}$ & Orphan sequence $^{\mathrm{a}}$ & $\begin{array}{l}\text { Unique ITS2, 94.2\%, 96.9\%, 2.14e-59 to: } \\
\text { AY843167, EF016376, EU725709 }\end{array}$ & Orphan sequence $^{\mathrm{a}}$ & $\begin{array}{c}\text { Ascomycota; } \\
\text { Herpotrichiellaceae } \\
\text { sp. }\end{array}$ \\
\hline $\begin{array}{l}\text { Léo2, } \\
\text { Léo4 and } \\
\text { Léo14 }\end{array}$ & $\begin{array}{l}94.9 \%, 100 \%, 1.82 \mathrm{e}-70 \text { to } \\
\text { EU686075 }\end{array}$ & Orphan sequences $^{\mathrm{a}}$ & $\begin{array}{c}96.3 \%-96.9 \%, 99.9 \%-100 \% 9.91 \mathrm{e}-68- \\
2.14 \mathrm{e}-69 \text { to } F N 555433\end{array}$ & Grouped together $^{\mathrm{b}}$ & $\begin{array}{l}\text { Ascomycota; } \\
\text { Herpotrichiellaceae } \\
\text { sp. }\end{array}$ \\
\hline $\begin{array}{l}\text { Léo1, } \\
\text { Léo13 and } \\
\text { Léo15 }\end{array}$ & $\begin{array}{c}\text { 100\%, 100\%, 5.02e-86 to } \\
\text { AY843170, EF016376, } \\
\text { EF016382-4, FJ553294 } \\
\text { and JN032522 }\end{array}$ & $\begin{array}{c}\text { AY843164-6, AY843168, } \\
\text { AY843170, AY843198, } \\
\text { EF016376, EF016382-5, } \\
\text { EU035408, EU725686, } \\
\text { EU725691, FJ553294, } \\
\text { FR682153, HQ211827, } \\
\text { HQ211891, JN032522 and } \\
\text { JX031869 }\end{array}$ & $\begin{array}{c}\text { 98.1\%-98.8\%, 96.9\%-100\%, 5.94e-70- } \\
\text { 2.11e-74 to EU516794, AY843164, } \\
\text { AY843166, AY843168, AY843198, } \\
\text { AY843170, EF016385, FJ553294 and } \\
\text { FR682153 }\end{array}$ & $\begin{array}{c}\text { FJ197877, EU516794, AY843164- } \\
\text { 8, AY843170, AY843198, } \\
\text { EF016376-86, FJ552708, } \\
\text { FJ552814, FJ553294, FR682153, } \\
\text { EU035408, EU725686, EU725691, } \\
\text { EU725709, HQ211827 and } \\
\text { HQ211891 }\end{array}$ & $\begin{array}{l}\text { Ascomycota; } \\
\text { Herpotrichiellaceae; } \\
\text { Cladophialophora } \\
\text { minutissima / C. } \\
\text { humicola }\end{array}$ \\
\hline Léo16 & $\begin{array}{c}86.9 \%, 98.8 \%, 5.18 \mathrm{e}-46 \\
\text { to EF433988, EU292482 } \\
\text { and JN889864 }\end{array}$ & Orphan sequence $^{\mathrm{a}}$ & $\begin{array}{c}91.6 \%, 100 \%, 4.78 \mathrm{e}-56 \text { to EU139143 and } \\
\text { EU139144 }\end{array}$ & Orphan sequence $^{\mathrm{a}}$ & $\begin{array}{c}\text { Ascomycota; } \\
\text { Herpotrichiellaceae } \\
\text { sp. } \\
\end{array}$ \\
\hline
\end{tabular}

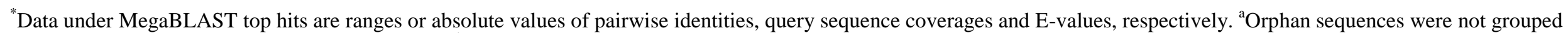
with any other sequences in BLASTclust analyses. ${ }^{b}$ These sequences grouped with each other but did not match with any sequences in GenBank. 
Supplementary Table S2. MegaBLAST hits and BLASTclust groups for ITS1 and ITS2 basidiomycete sequences generated using the ITS1F/ITS4 and ITS3Seb/TW13 primer pairs

\begin{tabular}{|c|c|c|c|c|c|c|}
\hline Sequences & $\begin{array}{l}\text { Primer } \\
\text { pair }\end{array}$ & $\begin{array}{l}\text { ITS1 MegaBLAST } \\
\text { top hit(s) }\end{array}$ & $\begin{array}{l}\text { ITS1 BLASTclust } \\
\text { group }\end{array}$ & $\begin{array}{l}\text { ITS2 MegaBLAST top } \\
\text { hit(s) }\end{array}$ & $\begin{array}{l}\text { ITS2 BLASTclust } \\
\text { group }\end{array}$ & Species inference \\
\hline \multirow[t]{2}{*}{$\begin{array}{l}\text { SG1-SG6, } \\
\text { SG14- } \\
\text { SG16, } \\
\text { Sig2-Sig8, } \\
\text { Sig13- } \\
\text { Sig16 and } \\
\text { Léo3 }\end{array}$} & $\begin{array}{c}\text { ITS1F/ } \\
\text { ITS4 }\end{array}$ & $\begin{array}{c}\text { 99.5\%-100\%, } \\
\text { 99.5\%-100\%, 9.31e- } \\
\text { 94-1.98e-95 to } \\
\text { GQ907084 and } \\
\text { GQ907097 }\end{array}$ & $\begin{array}{l}\text { GQ907083, } \\
\text { GQ907084, } \\
\text { GQ907097 and } \\
\text { GQ907138 }\end{array}$ & $\begin{array}{c}99.5 \%-100 \%, 100 \% \\
1.05 e-108-2.26 \mathrm{e}-110 \text { to } \\
\text { GQ907138 }\end{array}$ & $\begin{array}{l}\text { FN555434, } \\
\text { FN555435, } \\
\text { GQ907083 and } \\
\text { GQ907138 }\end{array}$ & \\
\hline & & & & & & $\begin{array}{c}\text { Basidiomycota; } \\
\text { Sebacinales clade } \\
\text { B }\end{array}$ \\
\hline $\begin{array}{l}\text { SG7-12, } \\
\text { Sig9- } \\
\text { Sig12, } \\
\text { Léo5, } \\
\text { Léo7-Léo9 } \\
\text { and Léo12 }\end{array}$ & $\begin{array}{l}\text { ITS3Seb } \\
\text { /TW13 }\end{array}$ & No ITS1 sequence & m.d. & $\begin{array}{c}99.1 \%-100 \%, 100 \% \\
4.87 \mathrm{e}-107-2.26 \mathrm{e}-110 \text { to } \\
\text { GQ907138 }\end{array}$ & $\begin{array}{l}\text { FN555434, } \\
\text { FN555435, } \\
\text { GQ907083 and } \\
\text { GQ907138 }\end{array}$ & \\
\hline
\end{tabular}




\section{Supplementary Figure legends}

Supplementary Fig S1 - mycothalli in rhizoid cells of Barbilophozia hatcheri from South Georgia. Images are of hyphae that have (a) penetrated the tip of a rhizoid (arrowed), (b) grown within the shaft of the cell and (c) formed a hyphal coil in its base (arrowed). Scale bars in each panel are $10 \mu \mathrm{m}$ in length. For clarity, the images are negatives of the originals, captured under UV epifluorescence at $\times 400$ magnification.

Supplementary Fig S2 - midpoint-rooted, maximum likelihood phylogram obtained from the alignment of ITS1-5.8S- ITS2 region sequences of ascomycetes amplified from Antarctic Barbilophozia hatcheri with those of fungi having $>75 \%$ ITS1 and ITS2 coverage and >85\% pairwise identity with query sequences. GenBank accession numbers of reference sequences are shown, along with unambiguously named fungal taxa, the plant species host or substrate and the country of origin in parentheses. Symbols at branch nodes indicate support at $>50 \%(\square)>80 \%(\circ)$ and at $100 \%(\bullet)$ in maximum parsimony and maximum likelihood analyses. Abbreviations: SG, South Georgia; Sig, Signy Island; Léo, Léonie Island. 
